\title{
ГОСУДАРСТВЕННО-ЧАСТНОЕ ПАРТНЕРСТВО В УПРАВЛЕНИИ СФЕРОЙ ФИЗИЧЕСКОЙ КУЛЬТУРЫ И СПОРТА
}

\author{
Н. В. Федорова, А. А. Волков \\ Московский гуманитарный университет
}

\begin{abstract}
Аннотация: В статье рассмотрены формы управления сферой физической культуры и спорта в России. Рассмотрены положительные и отрицательные факторы административного и гражданского управления в сфере физической культуры и спорта. Предложена система государственно-общественного управления сферой физической культуры и спорта, которая позволит учесть интересы общества и государства.
\end{abstract}

Ключевые слова: государственно-общественное управление; физическая культура и спорт; государственное муниципальное управление

\section{PUBLIC-PRIVATE PARTNERSHIP IN THE MANAGEMENT IN THE FIELD OF PHYSICAL CULTURE AND SPORT}

\author{
N. V. Fyodorova, A. A. Volkov \\ Moscow University for the Humanities
}

Abstract: The article considers the forms of management in the fied of physical culture and sport in Russia. Positive and negative factors of administrative and civil management in the sphere of physical culture and sport are considered. The authors propose a system of state and public management in the field of physical culture and sport, which will make it possible to consider the interests of both the society and state.

Keywords: state and public management; physical culture and sport; public municipal administration

\section{Введение}

В России на современном этапе сформировано три организационные формы осуществления управления в области физической культуры и спорта:

1. Собственно государственная форма управления, реализуемая через систему государственных органов (в первую очередь, органов исполнительной власти и местного самоуправления), которые реализуют управление физической культурой и спортом, а также государственными учреждениями физического воспитания по различным государственным программам;

2. Управление в физкультурно-спортивных общественных объединениях, в том числе, например, осуществление государственно-общественного контроля; 
Научные труды Московского гуманитарного университета 2019 № 1

3. Менеджмент спорта высших достижений, а также коммерческих организаций физкультурно-оздоровительной направленности (Алексеев, 2018).

Перечисленные формы управления в области физической культуры и спорта сегодня действуют, осуществляя свои функции, достаточно разрозненно, виду чего, согласование их действий представляется достаточно значимым.

Сложность в организации полноценного и комплексного взаимодействия различных форм управления состоит в том, что реализация этих форм регулируется, фактически, разными отраслями права - административным правом работа государственных органов власти в области физической культуры и спорта, и гражданским правом - в области предоставления услуг, инвестиций, иной коммерческой деятельности в области спорта (Иксанов, Селезнева, 2016).

Немаловажно учитывать и специфику управления сферой физической культуры и спорта в рамках различных форм. Так, государственная форма управления подразумевает использование властных полномочий, иерархическое подчинение объекта управления субъекту. При этом, общественное и коммерческое управление базируется на равноправном взаимодействии объекта и субъекта (Алексеев, 2014).

Следует отметить, что оба варианта взаимодействия в рамках управления сферой физической культуры и спорта имею положительные и отрицательные черты. Так в рамках государственной формы управления возможен более строгий контроль реализации отдельных процессов - например, осуществления государственных программ в сфере физической культуры и спорта. При этом, в рамках частного и общественного управления существует больше возможностей для проявления инициативы и творческого подхода в реализации проектов развития сферы физической культуры и спорта. Этому посвящена представленная статья.

В то же время, в рамках государственного (административного регулирования) сферы физической культуры и спорта неизбежно возникает проблема бюрократизма, жесткого планирования, негибкости управления. При этом частное и общественное управление не может использоваться в рамках проектов, заведомо не приносящих прибыли - в том числе и социальных проектов, которые объективно необходимы сегодня для развития сферы физической культуры и спорта (Иксанов, Селезнева, 2016).

Цель статьи - рассмотреть возможности уравновешивания положительных и отрицательных сторон государственного и частного и общественного управления в области физической культуры и спорта через создание системы государственно-частного партнерства.

Государственно-частное партнерство в области управления физиче- 
ской культурой и спортом сегодня становится объективно необходимым. Это обусловлено тем, что спорт и физическая культура становятся в современном мире одними из важнейших областей человеческой деятельности. Огромные достижения в области физической культуры и спорта, использование данной сферы в политике и экономике для привлечения инвестиций, легли в основу многих научно-технологических и социальных преобразований в обществе.

Спортивные события сегодня оказывают значительное влияние на общественные, экономические и политические процессы. В частности, допинговый скандал выявил отношение к России со стороны международного спортивного сообщества, как к стране, имеющей «дикие» убеждения, заведомо нарушающей установленные правила. Отчасти, это объясняется традиционным неприятием России в период существования СССР, когда идеология Советского Союза противостояла идеологии большинства капиталистических стран. Безусловно, такое отношение к нашей страны со стороны западных стран достаточно негативно сказывается не только на потенциальных дипломатических отношениях, но и на самоощущении и гражданской идентичности российского народа, как социальной общности «второго сорта».

В то же время, явная несправедливость к российским спортсменам со стороны международного сообщества, во многом является тем фактором, который способствует объединению и сплочению народа России против несправедливости (Алексеев, 2018). Кроме того, это показывает чрезмерную политизированность международного спорта, его явную зависимость от политических отношений, что несколько дискредитирует международное спортивное сообщество не только в глазах российских спортсменов, которые обижены явной несправедливостью, но и в глазах всего мира (Алексеев, 2014).

Немаловажным является и специфика трактовки ситуации с употреблением допинга, когда ошибка и нечестность нескольких конкретных спортсменов (которые были бы наказаны и со стороны России, и по всей вероятности, в любом случае не допущены на Олимпийские игры) негативно сказывается на всей российской олимпийской команде. Данный принцип «круговой поруки», конечно, несправедлив по отношению к спортсменам, не употребляющим допинг, но пострадавших в допинговом скандале, но в то же время, такая ситуация станет толчком к тому, чтобы формировать у российских спортсменов более высокий уровень социальной ответственности. В частности, складывается понимание того, что любая ошибка или мошенничество, отразится негативно не только на конкретном спортсмене, но и на все команде России, и в конечном счете - на имидже страны. Таким образом, допинговый скандал оказал, как отрицательное, так и положитель- 
ное влияние на российское спортивное сообщество и российский народ в целом. В частности, он поспособствовал росту социальной ответственности спортсменов и послужил фактором сплочения российского народа. Кроме того, допинговый скандал явно продемонстрировал излишнюю политизированность, и, следовательно, предвзятость международного спортивного сообщества (и Международный Олимпийский комитет в первую очередь) для всего мира.

В целом, спортивные скандалы по вопросам использования допинга ставят органы государственной власти и все российское общество перед осознанием необходимости рационального государственного регулирования сферы физической культуры и спорта (Братановский, 2008: 66).

Государственное регулирование в целом сферы физической культуры и спорта осуществляется сегодня государством через специализированные органы, в рамках их компетенций, но в строгом соответствии с законодательством (Конституции Российской Федерации, федеральных законов, указов Президента Российской Федерации и постановлений Правительства Российской Федерации, а также, иных нормативно-правовых актов (Иксанов, Селезнева,2016).

Но реализация государством системы управления сферой физической культуры и спорта не позволяет в полной мере реализовывать ключевые задачи управления, ввиду чего представляется необходимым внедрение качественно нового подхода в управлении рассматриваемой сферой.

Систему государственно-общественного управления можно представить следующим образом (см. рис.).

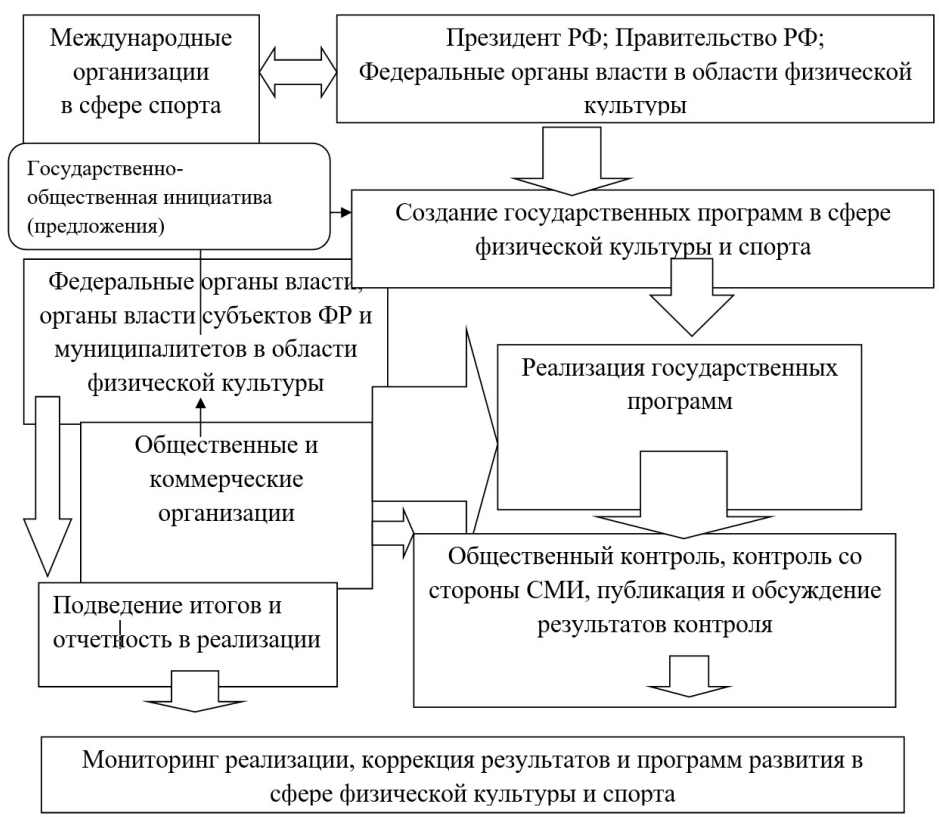

Рис. 1. Система государственно-общественного управления сферой физической культуры и спорта. 


\section{Заключение}

Можно отметить, что предложенная система государственно-общественного управления в сфере физической культуры и спорта позволит осуществлять более гибкое управление, а также более строгий контроль и мониторинг реализации государственных программ в сфере спорта - за счет совмещения механизмов государственного и общественного контроля (Иксанов, Селезнева, 2015).

Это согласуется со Стратегией развития физической культуры и спорта в России. Согласно принятой Стратегии развития физической культуры и спорта в Российской Федерации на период до 2020 г., главным в развитии сферы является создание условий, которые обеспечат возможность для граждан страны не только вести здоровый образ жизни, систематически заниматься спортом, но и участвовать в управлении данной сферой, выдвигать предложения по ее развитию и контролировать их исполнение (Братановский, 2008: 66).

Кроме того, это решит и текущую проблему - контроля приема фармацевтических средств спортсменами, а также контроля их поведения, что позволит повысить в целом социальную ответственность спортсменов. Такая социальная ответственность для спортсменов достаточно важна, поскольку они являются в отдельных случаях «лицом» российского народа на международной арене, а также примером для подрастающего поколения.

Немаловажным является и то, что сегодня государственно-общественное управление в сфере физической культуры и спорта, позволяет сделать спорт более доступным, а также дает возможность гражданам определять приоритетные направления и области развития спорта, его наиболее популярные и социально-значимые виды, на которые необходимо обратить внимание государства.

\section{СПИСОК ЛИТЕРАТУРЫ}

Алексеев, С. В. (2014) Спортивный менеджмент. Регулирование организации и проведения физкультурных и спортивных мероприятий [Электронный ресурс] : учебник / под ред. П. В. Крашенинникова. М. : ЮНИТИ-ДАНА ; Закон и право. 687 с.

Алексеев, С. В. (2018) Спортивное право России [Электронный ресурс] : учебник / под ред. П. В. Крашенинникова. 4-е изд., перераб. и доп. М. : ЮНИТИ-ДАНА ; Закон и право. 695 с

Братановский, С. Н. (2008) Система муниципального управления физической культурой и спортом в России: правовые основы организации и деятельности [Электронный ресурс] / под ред. В. А. Юсупова. Саратов : Изд-во Саратовского ун-та. 168 с. 
Иксанов, Р. А., Селезнева, А. Х. (2016) Защита прав и законных интересов граждан и организаций как правовая категория // Аграрное и земельное право. №1(133). С. 54-57.

Дата поступления: 20.12.2018 2.

Федорова Наталья Васильевна - кандидат экономических наук, доцент, профессор кафедры менеджмента Московского гуманитарного университета. Адрес: 111395, Россия, г. Москва, ул. Юности, д. 5, кор. 3, ауд. 612. Тел.: +7 (499) 374-70-13. Эл. адрес: kafedra612@mail.ru

Волков Артем Андреевич - студент магистратуры кафедры менеджмента Московского гуманитарного университета. Адрес: 111395, Россия, г. Москва, ул. Юности, д. 5. Тел.: +7 (499) 374-70-13. Эл. адрес: volkovtema17@ yandex.ru

Fedorova Natalya Vasilyevna, Candidate of Economics, Associate Professor, Professor, Department of Management, Moscow University for the Humanities. Postal address: 5, Yunosti St., Moscow, Russian Federation, 111395. Tel.: +7 (499) 374-70-13. E-mail: kafedra612@mail.ru

Volkov Artem Andreyevich, Graduate Student, Department of Management, Moscow University for the Humanities. Postal address: 5, Yunosti St., Moscow, Russian Federation, 111395. Tel.: +7 (499) 374-70-13. E-mail: volkovtema17@ yandex.ru

\section{Для цитирования:}

Федорова Н. В., Волков А. А. Государственно-частное партнерство в управлении сферой физической культуры и спорта [Электронный ресурс] // Научные труды Московского гуманитарного университета. 2019. № 1. URL: http://journals.mosgu.ru/trudy/article/ view/945 (дата обращения: дд.мм.гг.). DOI: 10.17805/trudy.2019.1.16 